Acknowledgement: Survey supported by Novartis

Disclosure of Interests: Laure Gossec Grant/research support from: AbbVie, BMS, Celgene, Janssen, Lilly, MSD, Novartis-Sandoz, Pfizer, Sanofi, and UCB, Consultant for: AbbVie, Biogen, BMS, Celgene, Janssen, Lilly, MSD, Nordic Pharma, Novartis-Sandoz, Pfizer, Roche, Sanofi, and UCB Consultant for: L Gossec has received honoraria from Celgene as investigator for this study, Pascal Claudepierre Consultant for: Honoraria from Novartis as steering committe of this survey, René-Marc Flipo Consultant for: Honoraria from Novartis as steering committe of this survey, Marco Garrido-Cumbrera Consultant for: Honoraria from Novartis as steering committe of this survey, Emilie Desfleurs Employee of: Employee of Novartis Pharma, Francoise Alliot Launois: None declared, LAURENT GRANGE Consultant for: Laurent Grange has received honoraria from Amgen, Lilly and UCB and research support from Lilly, Amgen, UCB, Expanscience, Mylan, Roche diagnostics and TEVA

DOI: 10.1136/annrheumdis-2019-eular.2741

\section{SAT0330 VALUE OF DIAPHRAGMATIC ASSESSMENT IN RELATION TO PULMONARY FUNCTIONS AND DISEASE ACTIVITY IN AXIAL SPONDYLOARTHROPATHIES: PRELIMINARY REPORT}

Seçilay Güneş ${ }^{1}$, Aysun Genç ${ }^{1}$, İsmihan Sunar ${ }^{2}$, Sevgi Esra Özdemir ${ }^{1}$, Derya Gökmen ${ }^{3}$, Şebnem Ataman ${ }^{2}$, Yesim Kurtais Aytür ${ }^{1} .{ }^{1}$ Ankara University School of Medicine, Physical Medicine and Rehabilitation, Ankara, Turkey, ${ }^{2}$ Ankara University School of Medicine, Physical Medicine and Rehabilitation,

Rheumatology, Ankara, Turkey; ${ }^{3}$ Ankara University School of Medicine, Biostatistics, Ankara, Turkey

Background: Axial Spondyloarthropathies (SpA) are chronic, systemic, inflammatory diseases which affect the axial skeleton, limit chest mobility and cause serious impairments in pulmonary functions.

Objectives: In this cross-sectional study, as a new approach; diaphragm thickness is assessed by ultrasound in patients with axial SpA to determine possible relationships with pulmonary functions and disease activity. Methods: 49 axial SpA patients enrolled in the study were assessed by Bath Ankylosing Spondylitis Disease Activity Index (BASDAI), Bath Ankylosing Spondylitis Functional Index (BASFI), Bath Ankylosing Spondylitis Metrology index (BASMI), Erythrocyte Sedimentation Rate (ESR), serum C-Reactive Protein levels (CRP) and chest expansion (cm). 15 patients with lung diseases other than axial SpA pulmonary involvement, neuromuscular diseases, scoliosis and congenital chest deformity were excluded. Dynamic pulmonary function tests (PFT) and 6 min walk (6MW) tests were done and physical activity levels were evaluated by short form International Physical Activity Questionnaire (IPAQ). Diaphragm thickness was measured at end expiration (dtFRC) and deep inspiration (total lung capacity (dtTLC)). Thickness ratio (dtr: dtTLC/dtFRC) and thickness change (dtc: dtTLC-dtFRC) were calculated.

Results: The descriptive data of the patients are presented in Table 1 Patients had a moderate disease activity and all the patients were category 1 (inactivity) according to IPAQ. Mean value of dtr and PFT seem to be within normal range according to population studies and dtr was significantly correlated with dynamic pulmonary function tests, yet negatively correlated with ESR (r: -0.466, p: 0.006). There was insignificant negative correlation with age, disease duration, BASDAI, BASFI, and BASMI.

Conclusion: To the best of our knowledge, this is the first study evaluating the relation between diaphragm thickness and pulmonary functions

Table 1. Baseline descriptive data characteristics of patients

\begin{tabular}{|c|c|}
\hline $\operatorname{Age}^{a}(y)$ & $46 \pm 10.7$ \\
\hline Female $(n, \%)$ & $26(76.5)$ \\
\hline Male (n,\%) & $8(23.5)$ \\
\hline Disease duration- month ${ }^{b}$ & $\begin{array}{l}60(3-300) \\
\text { Female Male }\end{array}$ \\
\hline $\mathrm{dtFRC}^{\mathrm{a}}(\mathrm{cm})$ & $0.17 \pm 0.40 .18 \pm 0.3$ \\
\hline $\mathrm{dtTLC}^{\mathrm{a}}(\mathrm{cm})$ & $0.34 \pm 0.90 .43 \pm 011$ \\
\hline$d t r^{a}$ & $1.9 \pm 0.32 .42 \pm 0.35$ \\
\hline BASFI ${ }^{b}$ & $4.7(0-8.5)$ \\
\hline BASMI $^{\mathrm{b}}$ & $1(0-9)$ \\
\hline BASDAl $^{\mathrm{b}}$ & $4.5(0.4-8.4)$ \\
\hline MASES $^{b}$ & $3.5(0-13)$ \\
\hline $6 \mathrm{MWT}^{\mathrm{a}}(\mathrm{m})$ & $438 \pm 105$ \\
\hline VCMax $^{a}$ & $3.2 \pm 0.8(95.09 \% \mathrm{~N})$ \\
\hline $\mathrm{FEV} 1^{\mathrm{a}}$ & $2.5 \pm 0.6(93.6 \% \mathrm{~N})$ \\
\hline $\mathrm{PEF}^{\mathrm{a}}$ & $6.0 \pm 1.6(87.4 \% \mathrm{~N})$ \\
\hline
\end{tabular}

with disease activity. Even though, there was no limitation in PFT and expected values were obtained in $\mathrm{dtr}$, the negative correlation with ESR makes us think about the possible effect of disease activity on dtr. With these preliminary results, it is early to conclude, but dtr assessment may be complementary to PFT and early measures to improve diaphragm function with specific exercises should be implemented in patients with axial SpA.

\section{REFERENCE}

[1] Carrillo-Esper R, Pérez-Calatayud ÁA, Arch-Tirado E, Díaz-Carrillo MA Garrido-Aguirre E4, Tapia-Velazco R, Peña-Pérez CA, Espinoza-de Los Monteros I, Meza-Márquez JM, Flores-Rivera OI, Zepeda-Mendoza AD, de la Torre-León T. Standardization of Sonographic Diaphragm Thickness Evaluations in Healthy Volunteers Respir Care 2016;61(7):920-4

a: mean \pm SD, b: median (min-max), MASES: Maastrich Ankylosing Spondylitis Enthesitis Score, VC: Vital Capacity, FEV: Forced Expiratory Volume, PEF: Peak Expiratory Flow, N: Normal

Disclosure of Interests: None declared

DOI: 10.1136/annrheumdis-2019-eular.6081

\section{SAT0331 THE DIAGNOSTIC UTILITY OF THE DETECTION OF EROSIONS IN SACROILIAC JOINTS IN PATIENTS WITH EARLY SPONDYLOARTHRITIS}

Dorra Ben Nessib ${ }^{1}$, Wafa Hamdi', Kaouther Maatallah ${ }^{1}$, Hend Riahi $^{2}$, Dhia Kaffel ${ }^{1}$, Hanene Ferjani ${ }^{1}$, Med Montacer Kchir'. ${ }^{1}$ Kassab Institute, Rheumatology, Manouba, Tunisia; ${ }^{2}$ Kassab Institute, Radiology, Manouba, Tunisia

Background: In the light of new therapeutic strategies, it has become essential to detect spondyloarthritis (SpA) in its earliest stages in order to initiate treatment as early as possible. Magnetic resonance imaging (MRI), with its ability to detect active lesions, is usually considered as a key tool for early recognition of sacroilitis. However, a growing number of studies reported the lack of specificity of bone marrow edema (BME) leading sometimes to a false "positive MRl" of sacroiliac joints (SIJ). In addition, many recent studies have pointed out the utility of detecting structural lesions, especially erosions, reported as the earliest structural change on SIJ in the course of sacroiliitis.

Objectives: We aimed to assess the reliability of early recognition of erosions in patients with suspected SpA.

Methods: Consecutive patients, aged 16 and over, consulting from February 2014 to February 2017 for symptoms suggestive of SpA (inflammatory back pain, enthesitis or dactylitis...) were enrolled in this cohort. They were referred for computed tomography (CT) and MRI of the SIJ. The CT and MR images were reviewed for the presence of erosions by 2 musculoskeletal radiologists blinded to clinical findings. After a follow-up of 2 years, 2 experienced rheumatologists confirmed or excluded the diagnosis of SpA. Diagnostic utility of erosions for diagnosis of SpA was determined by calculating sensitivity, specificity, positive and negative likelihood ratio with final clinical diagnosis made by rheumatologists as golden standard.

Results: Fifty-four patients were included, 13 men and 41 women. The mean age was 39 years [17-71]. The mean duration of symptoms was 75 months (6 years). Cervical, thoracic, lumbar and buttock pain were noted respectively in $46.3 \%, 37 \%, 87 \%$, and $57.4 \%$ of the studied patients. Morning stiffness was noted in $55.5 \%$ of patients. The prevalence of HLA-B27 was $23.4 \%$. After a follow-up of 2 years, the referring rheumatologists made a diagnosis of SpA in $77.8 \%$ of patients, whereas SpA was excluded in $22.2 \%$. Among the 42 patients classified as having a confirmed SpA, erosions were detected on SIJ by CT in $64.3 \%(n=27)$ and by MRI in $(n=18) 42.85 \%$ of patients. Among the 12 patients in whom Spa was excluded, erosions were detected on SIJ by CT in $25 \%$ $(n=3)$ of patients and were not detected by MRI in any patient. Sensitivity, specificity, positive and negative likelihood ratio of erosions detected by CT were respectively estimated at $64.3 \%, 75 \%, 90 \%$ and $37.5 \%$. Those of erosions detected by MRI were estimated at $42.9 \%, 100 \%$, $100 \%, \quad 33.33 \%$. A statistically significant association was observed between erosions and rheumatologists' diagnosis of SpA $(p=0.05$ for CT and $\mathrm{p}=0.012$ for $\mathrm{MRI}$ ). The likehood ratio was estimated respectively for $\mathrm{CT}$ and MRI at 3.8 and 7.6 .

Conclusion: In our study, detection of erosions showed a high specificity for recognition of sacroilitis, especially when detected by MRI. This study highlights the utility of structural SIJ lesions, particularly erosions, to reduce the number of false positives.

Disclosure of Interests: None declared

DOI: 10.1136/annrheumdis-2019-eular.6453 